\title{
ĐÁNH GIÁ TÌNH HÌNH SỬ DỤNG THUỐC CORTICOID TẠI KHOA NộI TỔNG HỢP BÊ̂NH VIỆN TRƯờ'NG ĐẠI HỌC Y DƯợC CẦN THƠ NĂM 2020
}

TÓM TẮT

Mục đích: Đánh giá tình hình sử dụng thuốc trong điều trị ngoại trú thông qua một số chî số sử dụng thuốc. Đối tượng và phương pháp: Nghiên cứu được thực hiện theo phương pháp mô tả cắt ngang với 400 hồ sở bệnh án. Kết quả: Tỷ lệ giới tính sư dung corticoid trong quá trình điều tri ở nam là $48 \%$ và nữ là $52 \%$. Nhóm tuổi lớn hơn hoặc bằng 60 tuổi $(68,75 \%)$ chiếm tỷ lệ cao nhất, thứ hai là nhóm tuổi từ 18-59 tuổi chiếm $30 \%$. Thời gian nằm viện trung bình của bệnh nhân là $6 \pm 2,73$ ngày. Methylprednisolone có tỷ lệ sử dụng cao nhất $(79,50 \%)$. Tỷ lệ sử dụng corticoid theo đường tiêm có tỳ lệ cao nhất $(64,75 \%)$. Tỷ lệ sử dung cho mục đích kháng viêm chiếm phần lớn tổng số bệnh án được khảo sát $(60,5 \%)$. Thời gian điều trị corticoid từ 1 đến 4 ngày là chiếm tỷ lệ cao nhất $(54,75 \%)$, thấp nhất là lớn hơn 14 ngày chiếm 5,5\%. Tỷ lệ bệnh án có chỉ định corticoid không phối hợp với non steroid chiếm đa số (86\%). Tỷ lệ tương tác thuốc mức độ nghiêm trọng xảy ra giữa của cortitoid với thuốc khác $(10,50 \%)$. Kết luận: nghiên cứu là tài liêu tham khảo cho các cán bô y tếvà lãnh đạo về tình hình kê đơn thuốc trong điêu trị ngoại trú tại 1 cơ sở y tế hạng III.

Tư khóa: Corticoid, tình hình sử dụng corticoid, tương tác thuốc.

\section{SUMMARY}

\section{ASSESSMENT THE SITUATION OF USING CORTICOSTEROIDS AT DEPARTMENT OF GENERAL INTERNAL MEDICINE AT CAN THO UNIVESITY OF MEDICINE AND PHARMACY HOSPITAL IN 2020}

Objective: Assessing the situation of drug use in outpatient treatment through some indicators of drug use. Subjects and methods: The study was carried out by cross-sectional descriptive method with 400 medical records. Results: The sex ratio of using corticosteroids during treatment was $48 \%$ in men and $52 \%$ in women. The age group older than or equal to 60 years old $(68.75 \%)$ accounted for the highest proportion, the second age group from 18-59 years old accounted for $30 \%$. The mean hospital stay of patients was $6 \pm 2.73$ days. Methylprednisolone had the highest utilization rate $(79.50 \%)$. The rate of using corticosteroids by injection had the highest rate $(64.75 \%)$. The rate of use for anti-inflammatory purposes accounted for the majority of the total

*Trường Đại học Y Dược Cần Thơ Chịu trách nhiệm chính: Nguyễn Phục Hưng Email: nphung@ctump.edu.vn Ngày nhận bài: 15/4/2021

Ngày phản biện khoa học: 3/5/2021

Ngày duyêtj bài: 22/5/2021 medical records surveyed $(60.5 \%)$. The duration of corticosteroid treatment from 1 to 4 days is the highest rate $(54.75 \%)$, the lowest is greater than 14 days, accounting for $5.5 \%$. The percentage of patients with indications for corticosteroids not combined with non-steroidal anti-inflammatory drugs accounted for the majority (86\%). The rate of serious drug interactions occurring between corticosteroids and other drugs $(10.50 \%)$. Conclusion: The study is a reference for medical staff and leaders on the situation of drug prescribing in outpatient treatment at a Grade III medical facility.

Keywords: Corticosteroids, situation of using corticosteroids, drug interactions.

\section{I. ĐẶT VẤN ĐỀ}

Corticoid được các bác sĩ sử dụng rộng rãi do có tác dụng chống viêm và ức chế miển dịch mạnh mẽ, corticoid là một trong những nhóm thuốc được dùng trong điều trị phổ biến nhất trên nhiêu bệnh cảnh lâm sàng, gần $1 \%$ dân số toàn cầu đang được điều trị với liệu pháp corticoid trong các bệnh lý khác nhau [7]. Là một loại thuốc có lợi ích rất lớn trong nhiều bệnh cảnh lẩm sàng và được xem như là một thần dược nhưng bên cạnh đó nhóm thuốc này tiềm ẩn rất nhiều những tác dụng phụ tác động trên hầu hết các hệ cơ quan và nhiêu tương tác bất lợi nếu phối hợp thuốc không tốt [8]. Tại bệnh viện Trường Đại học Y Dược Cần Thơ, việc kê đởn corticoid rất phổ biến và̀ rộng rãi. Vì vậy, với mong muốn tìm hiểu tình hình sử dụng thuốc corticoid trong điều trị nội trú tại khoa Nội Tổng Hợp để góp phần cải thiện hiệu quả điều trị, giảm tỷ lệ tử vong và rút ngắn thời gian nằm viện, chúng tôi thực hiện đề tài: "Đánh giá tìnhhình sử dụng thuốc corticoid tại khoa Nội Tổng Hợp bệnh viện Trường Đại học Y Dược Cần Thơ năm 2020" với 2 mục tiêu:

- Đánh giá đặc điểm sử dụng thuốc corticoid trong điều trị nội trú tại khoa Nội tông hợp bệnh viện Trường Đại học Y Dược Cần Thơ năm 2020.

- Đánh giá các tương tác thuốc có ý nghĩa lâm sàng của corticoid với các thuốc khác trong hồ sơ bệnh ánđiều trị nội trú tại khoa Nội tông hợp bệnh viện Trường Đại học Y Dược Cần Thơ năm 2020.

\section{II. ĐỐI TƯỢNG VÀ PHƯƠNG PHÁP NGHIÊN CỨU}

2.1. Đối tượng nghiên cứu. Hồ sơ bệnh án (HSBA) của bệnh nhân được chỉ định corticoid tại khoa Nội tổng hợp của bệnh viện Trường Đại 
học Y Dược Cần Thơ năm 2020 và được lưu trữ tại phòng Kế Hoạch Tổng Hợp.

\subsection{Phương pháp nghiên cứu}

2.2.1. Thiết kế nghiên cứu: phương pháp mô tả cắt ngang.

\subsubsection{Cõ̃ mẫu chọn}

- Cỡ mẫu: Số đơn thuốc cần thu thập:

$$
\mathrm{n}=\frac{Z_{(1-\alpha / 2) \cdot p \cdot(1-p)}^{2}}{d^{2}}
$$

Chọn $a=0,05$; tra bảng với $(1-a)=0,95$ thì $Z_{(1-\alpha)}=1,96$. Chon $d=0,05$.

Thay vào công thức trên, ta có $\mathrm{n}=385$. Nhóm nghiên cứu lấy 400 HSBA

- Cách chọn mẫu: lọc lấy danh sách bệnh án từ ngày $01 / 01 / 2020$ đến ngày $31 / 12 / 2020$ của bệnh nhân có chỉ định corticoid được điều trị nội trú tại khoa Nội Tổng Hợp thỏa mãn điều kiện của tiêu chuẩn lựa chọn và tiêu chuẩn loại trừ. Từ danh sách này chúng tôi tiến hành chọn ngẫu nhiên hệ thống 400 HSBA với giá trị khoảng hằng định $\mathrm{k}=2$.

\subsection{Nội dung nghiên cứu:}

Đặc điểm chung của mấu nghiên cứu: gồm nhóm tuổi, giới tính, số ngày điều trị.

Đặc điểm sử dụng corticoid: gồm tỷ lệ corticoid sử dụng (hoạt chất, đường sử dụng), tỷ lệ corticoid sử dụng theo nhóm bệnh, theo mục đích điều trị, tỳ lệ theo số ngày sử dụng corticoid, phối hợp với non steroid, tương tác thuốc có ý nghĩa lâm sàng.

Xác định tương tác có ý nghĩa lâm sàng của corticoid bằng các bước tra tương tác thuốc: nhập tên thuốc vào ô tra tương tác trên cả 2 trang website Drugs.com và trang Medscape.com. Chọn cặp TTT ở mỗi bệnh án có ý nghĩa lâm sàng. Nếu cặp tương tác xuất hiện trên cả 2 trang website thì chọn mức tương tác cao nhất.

Phương pháp xử lý và phân tích số liệu: số liệu được xử lý bằng SPSS 22.0.

\section{KẾT QUẢ NGHIÊN CỨU}

3.1. Đặc điểm chung của mẫu nghiên cứu. Phân bố bệnh nhân theo tuổi và giới tính trong nghiên cứu là có 192 bệnh nhân nam $(48 \%)$ và 208 bệnh nhân nữ (52\%). Phân bố bệnh nhân ở tất cả các nhóm tuổi, trong đó nhiều nhất là nhóm tuổi $\geq 60$ tuổi $(68,75 \%)$, tiếp đó là nhóm tuổi 18-59 tuổi (30\%), nhóm bện nhân phân theo nhóm tuổi có tỷ lệ thấp nhất là $\leq 17$ tuổi $(1,25 \%)$. Tuổi trung bình của các bệnh nhân là $64 \pm 18$.

Thời gian nằm viện: thời gian nằm viện trung bình của bệnh nhân là $6 \pm 2,73$ ngày.

3.2. Đánh giá đặc điểm sử dụng thuốc corticoid

Bảng 3.1. Tý lệ các loại corticoid được sử dụng

\begin{tabular}{|c|c|c|c|c|}
\hline Tên hoạt chất & Tên biệt dược & Hàm lượng & Dường dùng & Số lượng (\%) \\
\hline \multirow{4}{*}{ Methylprednisolone } & Depo-Medrol & $40 \mathrm{mg}$ & Thuốc tiêm & $2(0,5)$ \\
\cline { 2 - 5 } & Soli-medon & $40 \mathrm{mg}$ & Thuốc tiêm & $44(11)$ \\
\cline { 2 - 5 } & Solu-Medrol & $40 \mathrm{mg}$ & Thuốc tiêm & $136(34)$ \\
\cline { 2 - 5 } & Somidex & $40 \mathrm{mg}$ & Thuốc tiêm & $41(10,25)$ \\
\cline { 2 - 5 } & Medexa & $16 \mathrm{mg}$ & Uống & $37(9,25)$ \\
\cline { 2 - 5 } & Medrol & $16 \mathrm{mg}$ & Uống & $13(3,25)$ \\
\cline { 2 - 5 } & Methylsolon & $16 \mathrm{mg}$ & Uống & $45(11,25)$ \\
\hline \multirow{3}{*}{ Budesonide } & Pulmicort & $500 \mathrm{mcg}$ & Xịt & $23(5,75)$ \\
\hline Dexamethasol & Symbicort & $160 \mathrm{mcg}$ & Xịt & $9(2,25)$ \\
\cline { 2 - 5 } & Dexamethasol & $4 \mathrm{mg}$ & Tiềm & $1(0,25)$ \\
\hline \multirow{3}{*}{ Fluticasone } & Avamys & $27,5 \mathrm{mcg}$ & Xịt & $1(0,25)$ \\
\cline { 2 - 5 } & Seretide 25/250mg & $250 \mathrm{mg}$ & Xịt & $10(2,5)$ \\
\cline { 2 - 5 } & Seretide Evohaler 25/250mcg & $250 \mathrm{mcg}$ & Xịt & $3(0,75)$ \\
\hline \multirow{2}{*}{ Hydrocortisol } & Hydrocortisol & $100 \mathrm{mg}$ & Tiềm & $30(7,5)$ \\
\hline & Vinphason & $100 \mathrm{mg}$ & Tiêm & $5(1,25)$ \\
\hline Tống & & & & $\mathbf{4 0 0}(\mathbf{1 0 0})$ \\
\hline
\end{tabular}

Kết quả cho thấy loại hoạt chất corticoid được sử dụng nhiêu nhất là Methylprednisolone $(79,5 \%)$, hoạt chất corticoid sử dụng ít nhất là Dexamethasol $(0,25 \%)$. Corticoid được sử dụng đường tiêm chiếm tỷ lệ cao nhất $(64,75 \%)$, kế đến là dạng uống $(23,75 \%)$ và dạng xịt được sử dụng ít nhẩt chiếm $(11,5 \%)$.

Bảng 3.2. Tý lệ sử dụng corticoid theo mục đích sư dụng

\begin{tabular}{|c|c|}
\hline $\begin{array}{c}\text { Tỷ lệ sử dụng Corticoid theo } \\
\text { mục đú́ch sử dụng }\end{array}$ & $\begin{array}{c}\text { Số lượng } \\
(\%)\end{array}$ \\
\hline Chống dị ứng & $42(10,5)$ \\
\hline Kháng viêm & $242(60,5)$ \\
\hline Uc chế miên dịch & $97(24,25)$ \\
\hline
\end{tabular}


Diều trị/hô trợ điều trị các bệnh khác $19(4,75)$

\section{Tống số} 400(100)

Tỷ lệ sư dụng cho mục đích kháng viêm chiếm phần lớn tổng số bệnh án được khảo sát $(60,5 \%)$, kế đến là dùng cho mục đích ức chế miển dịch $(24,25 \%)$, hỗ trợ điều trị hoặc điều trị các bệnh khác là dùng trong các bệnh như ung thư, các bệnh ác tính, các bệnh về da và mắt chiếm tỷ lệ thấp nhất $(4,75 \%)$.

Bảng 3.3. Tỷ lệ sử dụng corticoid theo nhóm bệnh

\begin{tabular}{|c|c|}
\hline $\begin{array}{c}\text { Tỷ lệ sử dụng Corticoid } \\
\text { theo nhóm bệnh }\end{array}$ & $\begin{array}{c}\text { Số lượng } \\
(\mathbf{\%})\end{array}$ \\
\hline Hô hấp & $190(47,5)$ \\
\hline Nội tiết & $58(14,5)$ \\
\hline Dị ứng & $22(5,5)$ \\
\hline Tai Mũi Họng & $14(3,5)$ \\
\hline Cơ Xương Khớp & $48(12)$ \\
\hline Thận Tiết Niệu & $54(13,5)$ \\
\hline Khác & $14(3,5)$ \\
\hline Tống số & $\mathbf{4 0 0 ( 1 0 0 )}$ \\
\hline
\end{tabular}

Nhóm bệnh dùng corticoid gần phân nửa sô bệnh án kháo sát là bệnh hô hấp $(47,5 \%)$, corticoid dùng ở nhóm bệnh tai mũi họng và nhóm bệnh khác (tiêu hóa, mắt,...) cùng bằng tỷ lệ nhau $(3,5 \%)$.

Bảng 3.4. Tỷ lệ sử dụng theo số ngày điều trị bằng corticoid

\begin{tabular}{|c|c|}
\hline $\begin{array}{c}\text { Tỷ lể sử dưng theo số ngày } \\
\text { đîeu trị băng corticoid }\end{array}$ & $\begin{array}{c}\text { Số lượng } \\
\text { (\%) }\end{array}$ \\
\hline $1-4$ ngày & $219(54,75)$ \\
\hline $5-7$ ngày & $94(23,5)$ \\
\hline $8-14$ ngày & $65(16,25)$ \\
\hline$>14$ ngày & $22(5,5)$ \\
\hline Tống & $\mathbf{4 0 0 ( 1 0 0 )}$ \\
\hline
\end{tabular}

Thời gian điều trị corticoid từ 1 đến 4 ngày là chiếm tỷ lệ cao nhất $(54,75 \%)$, thấp nhất là lớn hơn 14 ngày chiếm 5,5\%.

Số bệnh án có phối hợp corticoid và thuốc kháng viêm non steroid là 56 bệnh án (chiếm $14 \%$ ) và không có phối hợp với non steroid là 344 bênh án (chiếm 86\%).

3.3. Đánh giá các tương tác thuốc có ý nghĩa lâm sàng của corticoid với các thuốc khác. Có 42 bệnh án trong 400 bệnh án khảo sát có ghi nhận có tương tác thuốc mức độ nghiêm trọng xảy ra giữa của cortitoid với thuốc khác $(10,50 \%)$.

Bảng 3.5. Các cặp tương tác thuốc của corticoid ở mức nghiêm trọng

\begin{tabular}{|c|c|c|}
\hline $\begin{array}{c}\text { Cặp tương tác mức } \\
\text { độ nghiêm trọng }\end{array}$ & Hậu quả & $\begin{array}{c}\text { Số } \\
\text { lượng } \\
(\%)\end{array}$ \\
\hline $\begin{array}{c}\text { Moxifloxacin - } \\
\text { Methylprednisolone }\end{array}$ & $\begin{array}{c}\text { Có thế gây viêm } \\
\text { gân và đứt gân }\end{array}$ & 4 \\
$(9,52)$ \\
\hline
\end{tabular}

\begin{tabular}{|c|c|c|}
\hline $\begin{array}{c}\text { Levofloxacin - } \\
\text { Methylprednisolone }\end{array}$ & & $\begin{array}{c}12 \\
(28,57)\end{array}$ \\
\hline $\begin{array}{l}\text { Levofloxacin - } \\
\text { Hvdrocortisol }\end{array}$ & & $\begin{array}{c}1 \\
(238)\end{array}$ \\
\hline $\begin{array}{l}\text { Levofloxacin - } \\
\text { Dexamethasol }\end{array}$ & & $\begin{array}{c}1 \\
(2,38)\end{array}$ \\
\hline $\begin{array}{c}\text { Ciproloxacin - } \\
\text { Methylprednisolone }\end{array}$ & & $\begin{array}{c}18 \\
(42,86)\end{array}$ \\
\hline $\begin{array}{l}\text { Ciproloxacin - } \\
\text { Hydrocortisol }\end{array}$ & & $\begin{array}{c}3 \\
(7,14)\end{array}$ \\
\hline $\begin{array}{l}\text { Iohexol - } \\
\text { Methylprednisolone }\end{array}$ & $\begin{array}{c}\text { Có thể làm tăng } \\
\text { nguy cơ co giật, } \\
\text { viêm màng não và } \\
\text { viêm màng tủy } \\
\text { sống }\end{array}$ & $\begin{array}{c}2 \\
(4,76)\end{array}$ \\
\hline \multirow[t]{2}{*}{$\begin{array}{l}\text { Ketoconazole - } \\
\text { Methylprednisolone }\end{array}$} & $\begin{array}{l}\text { Có thế làm tăng } \\
\text { đáng kể nồng độ } \\
\text { methylprednisolon } \\
\text { e trong máu }\end{array}$ & $\begin{array}{c}1 \\
(2,38)\end{array}$ \\
\hline & Tổng số & $\begin{array}{c}42 \\
(100)\end{array}$ \\
\hline
\end{tabular}

Tỷ lệ tương tác mức độ nghiêm trọng cao nhất và đáng chú ý nhất là Ciproloxacin Methylprednisolone $(42,86 \%)$. Kế đến là tương tác mức độ nghiêm trọng của cặp Levofloxacin Methylprednisolone (28,57\%).

\section{BÀN LUÂNN}

4.1. Đăc điểm bênh nhân trong mẫu nghiên cứu. Theo kết quả khảo sát thì tỷ lệ bệnh án bệnh nhân nam sử dụng corticoid là $48 \%$, nữ $52 \%$. Kết quả này có khác với một nghiên cứu tại bệnh viện đa khoa tuyến huyện ở Trà Vinh thì tỷ lệ nam là $38,6 \%$, nữa $61,4 \%$ [2] và kết quả nghiên cứu của Quách Thành Phúc (2013) tại bệnh viện huyện Thới Bình tỉnh Cà Mau với tỷ lệ nam (70\%) và nữ $(30 \%)$ [4]. Tỷ lệ nam và nữ ở các nghiên cứu có sự khác nhau điều đó có thể là do tỷ lệ bệnh tật ở từng vùng, từng khu vực, từng miển có cở cấu bệnh tật khác nhau.

Tỷ lệ bệnh nhân được chỉ định corticoid trong điều trị ở độ tuổi lớn hơn hoặc bằng 60 tuổi chiếm tỷ lệ cao nhất $(68,75 \%)$. Người cao tuổi thì chức nằng các cơ quan trong cơ thể bi suy giảm, sức đề kháng cũng giảm, bên cạnh đó còn do nhưng thói quen của nam như hút thuốc, rượu bia, lao động nặng bằng tay chân,... ̛̛̉ nữ thì vào giai đoạn mã̃n kinh, hoocmon nội tiết giảm mạnh dẫn đến dễ mắc bệnh. Nên kểt quả nghiên cứu tỷ lệ nhóm tuổi từ 60 tuổi trở lên là cao nhất là phù hợp.

4.2. Đặc điểm sử dụng corticoid trong mấu nghiên cứu. Theo bảng 3.1, Methylprednisolone có tỷ lệ sử dụng cao nhất 
(79,50\%), kết quả này phù hợp với nghiên cứu của Bùi Đức Thành (2014) [5] vì thuốc này tạo hiệu lực vừa đủ mạnh và có ít tác dụng phụ hơn các thuốc corticoid có tác dụng kéo dài. Tỷ lệ sử dụng corticoid theo đường tiêm có tỷ lệ cao nhất $(64,75 \%)$. Ở nước ta khí hậu nhiệt đới nóng ẩm chính là điều kiện thuận lợi cho các bệnh có liên quan đến hô hấp vì thế các bệnh đường hô hấp rất nhiều nên tỷ lê theo khảo sát corticoid dùng có bệnh hô hấp chiếm tỷ lệ cao nhất $(47,5 \%)$ là hợp lý. Kết quả này tương đồng với kết quả Quách Thành Phúc (2013) [4] cũng có kết quả sử dụng corticoid nhiều nhất ở nhóm bệnh hô hấp.

Từ kết quả bảng 3.4, thời gian sử dụng corticoid từ 1 đến 4 ngày chiếm tỷ lệ cao nhất $(54,75 \%)$, đây chưa phù hợp với thời gian trung bình điêu trị corticoid (5-7 ngày). Tuy nhiên, có thể là do yếu tố khách quan cũng ảnh hưởng không nhỏ đến thời gian điêu trị tại bệnh viện, như do sự quá tải của bệnh viện buộc thầy thuốc xem xét cho xuất viện sớm hay những trường hợp bệnh nhân xin về vì lý do cá nhân. Thời gian 8-14 ngày chiếm $16,25 \%$ là những trường hợp viêm nhiểm nặng như viêm phổi, hen phế quản bội nhiễm hay một số bệnh có tính chất mãn tính.

Phần lớn bệnh án sử dụng corticoid thì không có phối hợp với non steroid (86\%), còn bệnh án có phối hợp với non steroid trong quá trình điều trị $(14 \%)$. Từ kết quả này chúng ta có thể thấy được rằng tỷ lệ sử dụng thuốc corticoid trong quá trình trị liệu không có phối hợp với các thuốc kháng viêm non steroid chiếm tỷ lệ cao là phù hợp vì bản thân các thuốc corticoid là một trong những thuốc có tác dụng kháng viêm và ức chế miễn dịch mạnh, bên cạnh đó cũng có rất nhiều tác dụng phụ như loét dạ dày, hội chứng Cushing,... và bản thân nhóm thuốc này chủ yếu là điều trị triệu chứng. Các thuốc non steroid thì cũng có tác dụng giảm đau và kháng viêm nhưng cũng có tác dưng phụ gây loét dạ dày nên việc phối hợp sẽ dễ dẫn đến tình trang loét da dày nặng hoặc xuất huyết tiêu hóa. Ở đây bác sĩ vẫn có phối hợp corticoid và non steroid $(14 \%)$ chủ yếu ở các bệnh nhân mắc bênh cơ xương khớp để tăng tác dung giảm đau, kểt quả nghiên cứu của Nguyê̂n Thị Hằng (2006) cũng có kết quả phối hợp corticoid và non steroid tương tự [3].

4.3. Tương tác thuốc mức độ nặng của corticoid và các thuốc dùng chung. Tỷ lệ tương tác thuốc mức độ nghiêm trọng xảy ra giữa của cortitoid với thuốc khác $(10,50 \%)$. Kết quả nghiên cứu của Nabovati E (2014) về tương tác thuốc là mức độ nghiêm trọng là 7,90\% [6]. Kết quả nghiên cứu của Getachew H (2016) thì tương tác thuốc mức độ nặng chiếm 10\% [5]. Tỷ lệ nghiên của tương tác thuốc mức độ nặng của chúng tôi cao hơn có thể là do lý do chúng tôi nghiên cứu tại khoa Nội Tổng Hợp nên có nhiều đối tượng bệnh nhân, đa dạng về bệnh lý và nhiều loại thuốc dùng chung với corticoid dẫn đến tỷ lệ tương tác thuốc cao hơn.

\section{KẾT LUÂN}

Tỷ lệ giới tính sử dụng corticoid trong quá trình điều trị ở nam là $48 \%$ và nữ là $52 \%$.

Tỷ lệ bệnh án sử dụng corticoid theo nhóm tuổi, nhóm tuổi lớn hơn hoặc bằng 60 tuổi $(68,75 \%)$ chiếm tỷ lệ cao nhất, thứ hai là nhóm tuổi từ 18-59 tuổi chiếm 30\%.

Thời gian nằm viện: thời gian nằm viện trung bình của bệnh nhân là $6 \pm 2,73$ ngày.

Methylprednisolone có tỷ lệ sử dụng cao nhất (79,50\%). Tỷ lệ sử dụng corticoid theo đường tiêm có tỷ lệ cao nhất $(64,75 \%)$.

Tỷ lệ sử dụng cho mục đích kháng viêm chiếm phần lớn tổng số bệnh án được khảo sát $(60,5 \%)$, kế đến là dùng cho mục đích ức chế miến dịch $(24,25 \%)$, hỗ trợ điều trị hoặc điều trị các bệnh khác là dùng trong các bệnh như ung thư, các bệnh ác tính, các bệnh về da và mắt chiếm tỷ lệ thấp nhất $(4,75 \%)$.

Thời gian điêu trị corticoid từ 1 đến 4 ngày là chiếm tỷ lệ cao nhất $(54,75 \%)$, thấp nhất là lớn hơn 14 ngày chiếm $5,5 \%$.

Tỷ lệ bệnh án có chỉ định corticoid không phối hợp với non steroid chiếm đa số (86\%).

Tỷ lệ tương tác thuốc mức độ nghiêm trọng xảy ra giữa của cortitoid với thuốc khác $(10,50 \%)$.

\section{TÀI LIỆ THAM KHẢO}

1. Bùi Đức Thành (2014), Khảo sát tình hình sử dung thuốc corticoid tại bệnh viện đa khoa huyệ̂n Cẩm Giàng - Hải Dươning, Luận vằn dược sĩ chuyển khoa cấp I, Trường đai hoc Dước Hà Nồi.

2. Lê Quốc Thinh (2010), Chọn Glucocorticoid dùng ngoài để hạn chế tác hại, Bảng tin dược lâm sàng và điều trị, (1), Tr. 13.

3. Nguyễn Thị Hằng (2006), Khảo sát tác dung không mong muốn của glucocorticoid trên bệnh nhận mắc bệnh hệ thống điêu trị tại khoa dị ứng miển dịch lâm sàng - bệnh viện Bạch Mai, Luận văn chuyên khoa cấp I, Trưởng Đại học Dược Hà Nội.

4. Quach Thành Phúc (2013), KKhảo sát tình hình sử dụng thuốc corticoid trong điều trị tại bệnh viện đa khoa huyện Thới Bình tỉnh Cà Mau năm 2013, Luận văn chuyên khoa cấp I, Trường Đại Học Y Dược Cần Thơ.

5. Getachew H., Assen M., Dula F., et al. (2016). Potential drug-drug interactions in pediatric wards of Gondar University Hospital, Ethiopia: A cross sectional study. Asian Pacific Journal of Tropical Biomedicine, 6(6):534-538. 
6. Nabovati E., Vakili-Arki H., Taherzadeh Z., et al. (2014). Drug-drug interactions in inpatient and outpatient settings in Iran: a systematic review of the literature. Journal of Pharmaceutical Sciences, 22(52):257-261.

7. Nogué $M$, Rambaud J, Fabre $\mathbf{S}$ et all. Longterm corticosteroid use and dietary advice: a qualitative analysis of the difficulties encountered by patient. BMC Health Serv Res. 2019 Apr 26,19(1): 255.

8. Oray M, Foster CS, Ebrahimiadib N. Long-term side effects of glucocorticoids. Expert Opinion on Drug Safety,January 2016,15(4): 457-65.

\section{ĐÁNH GIÁ MộT SỐ YẾU TỐ LIÊN QUAN ĐẾN KIẾN THỨC VỀ DỰ PHÒNG ĐộT QUỴ NÃO CỦA NGƯỜI CAO TUỔI ĐANG ĐIỀU TRI ĐÁI THÁO ĐƯỜNG TẠI BỆNH VIỆN NộI TIẾT TRUNG ƯƠNG NĂM 2020}

\section{TÓM TẮT}

Mục tiêu: Đánh giá một số yếu tố liên quan đến kiến thức về dự phòng đột quy não của người cao tuổi đang điều trị đái tháo đường. Đối tượng và phương pháp: Người cao tuổi đang điều trị đái tháo đường. Nghiên cứu mô tả cắt ngang. Kết quả: Tuổi, thời gian mắc bệnh, giới tính, nghề nghiệp, tiền sử gia đình có người mắc bệnh đột quy não không có mối liên quan với kiến thức về dự phòng bênh của đối tượng nghiên cứu với $p>0,05$. Trình độ học vấn, nguồn thông tin nhân được, chỉ số xét nghiêm (HbA1C, Cholesterol, Triglycerid) có mối liên quan với kiến thức dự phòng đôt quy não của đối tượng nghiên cứu với $p<0,05$. Kết luận: Trình độ học vấn, nguồn thông tin nhận, các chì số xét nghiệm có mối liên quan có ý nghĩa thống kê với kiến thức về dự phòng đột quy não của đối tương nghiên cứu

Tư khóa: Đái tháo đường, đột quỵ não, dự phòng đột quy não

\section{SUMMARY}

EVALUATION OF SOME FACTORS RELATED TO THE KNOWLEDGE OF PREVENTIVE STROKE

\section{ELDERLY ARE TREATED IN HOSPITAL} DIABETES ENDOCRINOLOGY 2020

Objectives: To evaluate a number of factors related to knowledge about brain stroke prevention among the elderly in treating diabetes. Subjects and method: The elderly are being treated for diabetes. Cross-sectional descriptive research. Results: Age, duration of illness, sex, occupation, family history of someone with cerebral stroke were not correlated with study subjects' knowledge of disease prevention with $p>0.05$. Educational attainment, received information sources, test indexes (HbA1C, Cholesterol, Triglycerid) were related to knowledge of brain stroke prevention

*Trường Đại học Điều dưỡng Nam Định Chịu trách nhiệm chính: Đỗ Thị Thu Hiền Email: thuhien80tnd@gmail.com Ngày nhân bài: 11/4/2021

Ngày phản biện khoa học: 8/5/2021

Ngày duyệt bài: 21/5/2021

\author{
Đỗ Thị Thu Hiền*, Trương Tuấn Anh* \\ Vũ Thị Dung*, Ngô Thị Thục Nhàn*
}

of study subjects with $p<0.05$. Conclusion: Education levels, sources of information received, and test indicators were statistically significant with the study subjects' knowledge of brain stroke prevention.

Keywords: Diabetes, brain stroke, prevention of brain stroke.

\section{I. ĐẶT VẤN ĐỀ}

Đột quy. não là một vấn đề sức khỏe trên toàn thế giới và là tác nhân chính gây ra bệnh tât, tử vong và tàn tât ở cả các nước phát triển và đang phát triển. Theo Trung tâm kiểm soát và phòng ngừa dịch bệnh, đột quy não là nguyên nhân hàng đâu gấy ra khuyết tật có thể phòng ngừa trên toàn thế giới [5]. Bệnh gây ra hậu quả nghiêm trọng đối với sức khỏe và chất lượng cuộc sống của những người sống sót sau đột quy não và những người chăm sóc họ [7]. Ở Việt Nam, theo thống kê của Bệnh viện Nội tiết Trung ương, năm 2012 tỷ lệ mắc đái tháo đường là $5,4 \%$ [1],[3].

Bệnh đái tháo đường cũng là một yếu tố nguy cơ có thể thay đổi đối với đột quy;; những người mắc bệnh đái tháo đường được cho là có nguy cơ đột quy. gấp 1,5 đến 3 lần so với những người không mắc bênh đái tháo đường. Tỷ lệ bênh đái tháo đường đang gia tăng ở nhiêuu nước đang phát triển một phân là do sự ưa thích ngày càng tăng đối với chế độ ăn uống không hợp lý.

Trong khi đó, theo thống kê cưa Liên đoàn Đái tháo đường quốc tế (IDF/International Diabetes Federation) năm 2015 Thế giới có khoảng 415 triệu người mắc bệnh đái tháo đường, trong đó $90 \%$ là đái tháo đường type II và hay gặp ở người cao tuổi. Tại Hoa Kỳ tỷ lệ mắc đái tháo đường ở độ tuổi 45-64 tuổi là $16,2 \%$ trong khi ở những người 60-79 tuổi là 25,9\% [8]. Kết quả nghiên cứu dịch tễ học đột quy. não ở khu vực Đông Á cho thấy tỷ lệ mắc đột quy. não ở những người trên 65 tuổi là 